Volume 5

Issue 4 - Patient Self-Management

Article 1

$10-29-2018$

\title{
Patient Self-Management: Tools and Barriers
}

Dennis J. Baumgardner

Follow this and additional works at: https://aah.org/jpcrr

Part of the Diseases Commons, Health Services Research Commons, Primary Care Commons, and the Public Health Education and Promotion Commons

\section{Recommended Citation}

Baumgardner DJ. Patient self-management: tools and barriers. J Patient Cent Res Rev. 2018;5:253-5. doi: 10.17294/2330-0698.1660

Published quarterly by Midwest-based health system Advocate Aurora Health and indexed in PubMed Central, the Journal of Patient-Centered Research and Reviews (JPCRR) is an open access, peer-reviewed medical journal focused on disseminating scholarly works devoted to improving patient-centered care practices, health outcomes, and the patient experience. 


\title{
Patient Self-Management: Tools and Barriers
}

\author{
Dennis J. Baumgardner, MD | Editor-in-Chief \\ Department of Family Medicine, Aurora UW Medical Group, Aurora Health Care, Milwaukee, WI
}

"Making appointments with yourself and scheduling other things around them is key to proactive self-management."

- Michael S. Hyatt, author/speaker/former CEO

"We are what we repeatedly do. Excellence, then, is not an act, but a habit."

- Aristotle

$\mathrm{T}$ his spring, in volume 5, issue 2 of the Journal of Patient-Centered Research and Reviews (JPCRR), I wrote about the important topic of shared clinical decision-making. ${ }^{1}$ An essential component of patient-centered health care, shared decision-making combines clinical evidence and patient preferences to tailor diagnostic testing and treatment plans to each individual. What is the next logical step following patient-engaged decisionmaking? Patient self-management!

Self-management as presently conceptualized is a relatively new term. In 1996, Gruman and Von Korff defined it as "engaging in activities that protect and promote health, monitoring and managing the symptoms and signs of illness, managing the impact of illness on functioning emotions and interpersonal relationships and adhering to treatment regimens." ${ }^{2} \mathrm{~A}$ more basic definition, as related in this issue's article by Nease et al, ${ }^{3}$ was offered by Lorig and Holman in 2003: "patients' efforts to engage in behaviors to manage their

Correspondence: Dennis J. Baumgardner, MD,

Aurora Sinai Medical Center, 1020 N. 12th Street, \#4180, Milwaukee, WI 53233 (dennis.baumgardner@aurora.org) chronic illness." ${ }^{4}$ Indeed, self-management programs on the whole have been successful in improving outcomes regarding serious chronic illnesses such as diabetes and hypertension. . $^{\text {c. }}$.

Obviously, introducing self-management programs into primary care clinics

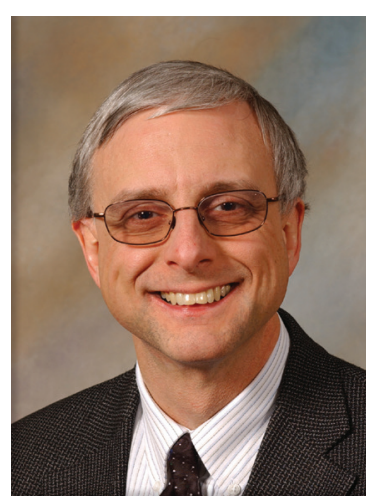
requires a plan and supportive tools. The editors of $J P C R R$ felt strongly enough about the importance of this topic that we devoted this issue to it, featuring, among others, 5 articles borne of the Improving Networks' Self-management Tools Through Engaging Patients and Practices (INSTTEPP) trial. ${ }^{6}$ Collectively, these works describe the implementation of patient self-management support (SMS) tools in 16 small to medium-sized primary care practices associated with 4 regional research networks, utilizing previously reported boot camp translation methods.

Nease et al analyzed the quantitative outcomes of 297 patients and 89 clinicians and staff in the practices following implementation of SMS. ${ }^{3}$ Compared to control patients, the intervention patients experienced significant improvements in self-rated health and on survey items indicative of process of care outcomes. The authors call for a longer and larger trial to investigate other potential improvements and, presumably, to demonstrate the sustainability of improved outcomes.

Fernald and colleagues then describe the results of their qualitative analysis of interviews and observations within the practices implementing the "communitycreated" SMS tools. ${ }^{7}$ Their findings focused on the 
critical conditions and factors needed for successful implementation of locally selected and adapted SMS tools in these modest-sized primary care practices. Analysis indicated that $38 \%$ of involved practices were able to at least partially implement SMS tools. It appeared that an active clinic champion, a clinic infrastructure supportive of innovation and change, and alignment of SMS changes with existing workflows of the clinic were critical to successful implementation.

In a novel brief report, Daly et al describe an early step in the research process, attempting to streamline institutional review board (IRB) approval of the selfmanagement tool implementation project in multiple geographically dispersed clinics. ${ }^{8}$ As an individual who oversees an IRB office, I am sensitive to the fact that some investigators simultaneously hear the word "delay" when hearing the word "IRB"; however, it does not have to be that way. A conscientious and wellprepared IRB submission and a customer-oriented IRB office often results in a pretty efficient process. That said, a widespread project as vast in scope and ambition as INSTTEPP certainly increases the potential for prolonged review periods and regulatory redundancies. Daly et al take us through the process of ceding project oversight to a central IRB, sharing lessons learned along the way. ${ }^{8}$ Considering the rising trend of multisite research studies, which, as the authors note, will soon be mandated for many federally funded studies, this brief report should prove a valuable resource for researchers in all health fields.

In their "how to" study, Simpson and colleagues analyzed the process of creating and adapting SMS tools utilizing resources from the Agency for Healthcare Research and Quality's SMS library. Their experience was that none of the library resources or tools was suitable for use in implementation of SMS without some degree of modification. ${ }^{9}$ In the remaining article from this series, Fagnan and colleagues describe the actual process of using a stepped-wedge trial design to roll out the adapted SMS tools in the various practices using expedited ( 2 months vs the usual 6 months) boot camp translation methods. ${ }^{10}$ Simple metrics and qualitative outcomes suggesting the value of this implementation are reported. Five themes emerged from patients and staff regarding patient needs and desires concerning self-management: shared responsibility, sense of empowerment, respectful communication, patient-centered quality measures, and guidance that is consistent with evidence and patient preferences.

Two additional articles - unrelated to INSTTEPP but squarely centered on patient self-management - grace this issue. Weight management is a significant area in need of improved patient self-management. cf.11-13 $^{-13}$ Bowie and colleagues report the findings of their focus group study of perceived barriers to weight loss among overweight or obese African American women in Milwaukee, Wisconsin. ${ }^{14}$ Issues of food choices were pervasive. Other primary barriers involved lifestyle changes, social support, locus of control, and health education. Representative quotes in the manuscript indicate that all of these barriers, quite understandably, impact success of weight self-management. A recent qualitative study of weight management in African American type 2 diabetics (of whom 10 of 12 were women) indicated that social support was the "most effective strategy for weight management when problems, stress, and challenges occur."15

Heart failure (HF) is another chronic disease for which patient self-management is deemed important, ${ }^{16,17}$ although a recent meta-analysis reported that no single intervention program characteristic could have an impact on all common clinical endpoints, nor was any program characteristic clearly associated with better outcomes of HF self-management interventions. ${ }^{18}$ Following up a previous publication, ${ }^{19}$ Grant and Graven add to this theme issue with a mixed-methods study of patient experiences in months 2 and 3 following hospitalization for $\mathrm{HF}^{20}{ }^{2}$ Managing treatment and $\mathrm{HF}$ symptoms were the most common problems identified during this time period. Barriers such as negative emotions/moods, difficulty coping, and inadequate resources also were identified.

Harkening back to the complexity inherent to shared decision-making caused by uncertainty and competing priorities, the authors noted HF patients expressed uncertainty about the future and even "hopeful" uncertainty about their diagnosis. ${ }^{20}$ Their findings also suggested that competing, but interrelated, problems like financial insecurity impacted $\mathrm{HF}$ self-management. Family-based interventions were suggested for improved self-care. As a longtime family 
medicine physician, I know all too well the struggles and frustrations faced by patients and clinicians alike in the quest for sufficient self-management of chronic disease. Perhaps these proposed interventions, along with understanding and addressing barriers, ${ }^{14}$ and implementation of properly selected evidence-based SMS tools ${ }^{3,9,10}$ can improve patient self-management of HF, obesity, and other major illnesses.

\section{References}

1. Baumgardner DJ. Uncertainty and competing priorities in shared clinical decision-making. J Patient Cent Res Rev. 2018;5:137-9. CrossRef

2. Gruman, J, Von Korff, M. Indexed bibliography on selfmanagement for people with chronic disease. Washington, DC: Center for Advancement in Health, 1996.

3. Nease DE Jr, Daly JM, Dickinson LM, et al. Impact of a boot camp translation intervention on self-management support in primary care. J Patient Cent Res Rev. 2018;5:256-66.

4. Lorig KR, Holman H. Self-management education: history, definition, outcomes, and mechanisms. Ann Behav Med. 2003;26:1-7. CrossRef

5. Chodosh J, Morton SC, Mojica W, et al. Meta-analysis: chronic disease self-management programs for older adults. Ann Intern Med. 2005;143:427-38. CrossRef

6. ClinicalTrials.gov. Implementing Networks Self-management Tools Through Engaging Patients and Practices (INSTTEPP). Last update posted 2016 Jun 28. https://clinicaltrials.gov/ct2/ show/NCT02815020. Accessed July 31, 2018.

7. Fernald DH, Simpson MJ, Nease DE Jr, et al. Implementing community-created self-management support tools in primary care practices: multimethod analysis from the INSTTEPP study. J Patient Cent Res Rev. 2018;5:267-75.

8. Daly JM, Harrod TW, Judge K, et al. Practice-based research networks ceding to a single institutional review board. J Patient Cent Res Rev. 2018;5:304-10.

9. Simpson MJ, Daly JM, Fernald DH, et al. How to translate self-management support tools into clinical practice. J Patient Cent Res Rev. 2018;5:276-86.
10. Fagnan LJ, Simpson MJ, Daly JM, et al. Adapting boot camp translation methods to engage clinician/patient research teams within practice-based research networks. J Patient Cent Res Rev. 2018;5:298-303.

11. Hall KD, Kahan S. Maintenance of lost weight and long-term management of obesity. Med Clin North Am. 2018;102:183-97. CrossRef

12. Laitner MH, Minski SA, Perri MG. The role of selfmonitoring in the maintenance of weight loss success. Eat Behav. 2016;21:193-7. CrossRef

13. Kong A, Beresford SAA, Alfano CM, et al. Self-monitoring and eating-related behaviors are associated with 12-month weight loss in postmenopausal overweight-to-obese women. J Acad Nutr Diet. 2012;112:1428-35. CrossRef

14. Bowie O, Kusch J, Morris GL 3rd, et al. Patient barriers for weight management among African American women. $J$ Patient Cent Res Rev. 2018;5:287-97.

15. Fitzpatrick SL, Hill-Briggs F. Strategies for sustained weight management: perspectives from African American patients with type 2 diabetes. Diabetes Educ. 2017;43:304-10. CrossRef

16. Riegel B, Moser DK, Buck HG, et al. Self-care for the prevention and management of cardiovascular disease and stroke: a scientific statement for healthcare professionals from the American Heart Association. J Am Heart Assoc. 2017;6(9):e006997. CrossRef

17. White MF, Kirschner J, Hamilton MA. Self-care guide for the heart failure patient. Circulation. 2014;129:e293-4. CrossRef

18. Jonkman $\mathrm{NH}$, Westland $\mathrm{H}$, Groenwold $\mathrm{RH}$, et al. What are effective program characteristics of self-management interventions in patients with heart failure? An individual patient data meta-analysis. J Card Fail. 2016;22:861-71. CrossRef

19. Grant JS, Graven LJ, Fuller K. Problems experienced in the first month after discharge from a heart failure-related hospitalization. J Patient Cent Res Rev. 2018;5:140-8. CrossRef

20. Grant JS, Graven LJ. Problems experienced in the second and third months after discharge from a heart failure-related hospitalization. J Patient Cent Res Rev. 2018;5:311-6.

(C) 2018 Aurora Health Care, Inc. 